Diagnosis : Cystoma of the right ovary.

Operation, March 30th. On opening the abdomen a large tibroid was found. Cervix, after removal of fibroid at the internal os, was sewed over and over with silk. 'This stump was covered over with peritoneum held in place by fine silk. No drainage. Uterine cavity almost wholly obliterated by the fibroid.

Discharged April 20th. Well.

Convalescence was uninterrupted.

August 1, 1895. Still remains well.

The fibroid was as large as a fetal head. The ovaries were large and flattened. Each measured three inches long by one and three-quarters inches wide.

CaSE II. J. W. W., aged forty years, married, white.

Present Complaint: Constant pain for six weeks in the abdomen below the umbilicus. Constant feeling of pressure in abdomen. Indigestion, constipation, sleeplessness.

Marital History: Married six years. One child three years ago. One abortion five years ago.

Menstruation began at fifteen years; flow slight, lasting two days, always irregular, no pain.

Present Illness: Nervous, thin and worried. Four years ago discovered the tumor.

Operation, April 1st. The fibroid was as large as the uterus at seven months. The uterus was cut off at the internal os and the cervix sewed over and over and covered with peritoneum as in Case No. I. No drainage.

Discharged April 28th. Well.

August 1, 1895. Strong and well. Doing her housework.

CASE III. A. S., aged forty-four years, married, white.

Present Complaint: For the past four years has had frequent flowing spells caused by excitement or fright, or jolting on riding in the street-cars. Much reduced in bealth and strength.

Marital History: Two children. Two miscarriages.

Menstruation began at thirteen years ; flow profuse, lasting seven days, regular. Severe dysmenorrhea.

Present Illuess: Jaundiced from head to foot. The eyes were a bright yellow, and the skin covering the face and body was of a dirty, yellowish-white color. This suggested carcinoma; but Dr. John L. Morse, after a careful examination of the blood, excluded can. cer and attributed the color of the skin to anemia from loss of blood.

Diagnosis : Fibroid, the size of a football.

Operation, April 10th. The uturus was cut off at the internal os, and the cervix sewed over and over and covered with peritoneum, as in Case No. I. No drainage. Convalescence was uninterrupted.

Discharged May 9th. Well.

CASE IV. S. S., aged forty-two years, widow, white.

Present Complaint: Backache, with flowing off and on for three years. Unable to work.

Present lliness: Has been losing strength for some months. During what she supposed was her last menstrual period she lost so much blood that her life was despaired of.

Diagnosis: Fibroid of the uterus, the size of a cocoanut.

Operation, May 14th. The uterus was cut off at the internal os, and the cervix sewed over and over and covered with peritoneum, as in Case No. I. No drainage. In this case nothing but catgut was used within the peritoneal cavity.

Convalescence: For twenty-four hours ber condition was perfectly satisfactory. Suddenly her pulse shot up to 120 and 130 ; and in spite of all we could do she died on the third day.

Autopsy : No distention of the abdomen. Very little fluid within the abdominal cavity. No blood. Stumps looked healthy. No flakes of lympb. No evidences of peritonitis.

Discharged May 17th. Dead.

\section{RAPID INCREASE OF OPACITY IN SENILE CATARACTS.}

\author{
BY F. W. ELLIS, M.D., MONSON, MAsE.
}

Senile cataracts, as a rule, develop very slowly. The opacity may increase almost imperceptibly from month to month, but it is never safe to predict what the course of the disease will be. Many of the standard text-books of ophthalmology mention the impossibility of an accurate forecast of events in the development of a cataract, and state that a cataractous lens, which has remained comparatively clear for a long time, may become completely opaque in a few months, or even weeks. The possibility of such an occurrence should always be borne in mind in making a prognosis.

It may not be so generally known that the time requisite for rendering an incomplete cataract entirely opaque may be extremely short - much less, in fact, than the few weeks frequently stated as the extreme limit. I do not remember ever having seen any statement in ophthalmological literature to this effect, but my own limited experience has demonstrated that it is possible for a cataractous lens still permitting a very considerable amount of vision to become entirely opaque, without any obvious cause, in a very few days. It does not seem likely that the masters of our profession have not noted similar occurrences in their vast experience, but it is singular that treatises on eye diseases are universally silent upon this point. It may be profitable to mention a few cases that have presented themselves to me in my practice, which have more or less interest in this connection.

In October, 1890, I was consulted by a gentleman sixty-six vears of age. I found that the vision of his right eye was $\underset{\mathbf{c}}{4}$, and that of his left $\underset{\mathbf{L x x}}{20}$. The right eye contained a well-advanced cataract, and the lens of the other showed traces of the same disease. I saw the patient at intervals after that, but made no record of his condition until April, 1894. 'The patient had been able to get about alone, and could read and write with difficulty. He noticed one day in the latter part of April that his vision was rapidly failing. $\mathrm{He}$ came to my office in great alarm. I found with the ophthalmoscope that the opacity had greatly increased, although I could still obtain a slight reflex from the fundus. A day or two later the lens became greatly swollen and entirely opaque, and the patient was led about the streets almost entirely blind. He was deeply sensible of his affliction as he had been able to read a letter only a few days before. No cause for the sudden change in the condition of the left eye could be discovered. As the cataract in the right eye was fully ripe, I removed it a few days later, with ex- 
cellent resultant vision. I have not yet operated upon the left eye, as the patient is well satisfied with his present vision. If he consents to the operation, I shall be greatly interested in its result. In this case there was no chance for error, as the patient was wholly dependent upon his left eye for vision, and was consequently able to note almost the moment when the remarkable change in its lens began.

While treating the patient whose record $I$ have just given, I was consulted by a lady, aged sixty-eight, whose lenses showed the commencement of cataract. A few months later, I found a large, swollen cataract in the right eye. The condition of the left eye had not greatly changed. The right lens was completely opaque, and the anterior chamber very shallow. The patient asserted that the change in her eye took place very suddenly, but, as she still possessed considerable vision in her other eye, it is obviously impossible to indicate with the certainty of the preceding case the time when the lens became completely cataractous. There is little doubt that the change was very abrupt. As in the preceding case there was no apparent cause for the occurrence. The condition of the left eye had not greatly changed. I removed the cataract by simple extraction, last May, and a few weeks later her vision was $2_{\mathbf{L}}^{0}$.

June 1, 1895, I extracted a large, very opaque cataract from the right eye of a woman aged fifty-seven. The result was most excellent, but could not be accurately recorded, as the patient could not read. The left eye had been destroyed by small-pox when the patient was a child. It was stated that the vision had been considerably impaired for a long time, but was suddenly lost about five months previously. Up to that time, the patient had been able to do her work at home, but in a day or two she was unable to move about without assistance, and rapidly became entirely blind. As the patient had but one eye, there could be no mistake as to the time when the great change in the transparency of the lens took place.

Although the two last cases are not so remarkable as the first, they are nevertheless significant. In all the cases there was a large, swollen lens, and a shallow anterior chamber. In each there was a sudden loss of vision in the affected eye. In the two instances in which the cataracts were removed the fundi were found normal.

Although we may not have data enough for profitable speculation as to the causes of these remarkable changes in senile cataracts, it may be allowable to consider the possibility of a rupture of the capsule of the lens at some point, due to the pathological process. Although we have no proof of such an occurrence in these cases, such an accident would serve very well to explain their peculiar features.

I have ventured to call the attention of readers of the JoURNAL to this subject in order that more careful attention may be given to the study of cases of the character I have described.

A Japanese Surgeon Honored by the Emperor of China. - The surgeon to the Mikado, who dressed the wound of Li-Hung-Chang after the attack made upon the Chinese plenipotentiary at Simonoseki, has at Li's request had the Order of the Double Dragon, Third Civil Class, conferred upon him by the Emperor of China.

\section{AN UNUSUAL CASE OF AORTIC REGURGITA- TION. \\ BY HERMAN F. VICKERY, M.D. \\ Instructor in Clinical Medicine, Harvard University.}

ON February 18, 1895, I had the honor of exhibiting to the Boston Society for Medical Improvement a patient who had presented himself in my service at the Massachusetts General Hospital, three days before, with a rather remarkable story and interesting physical signs.

The man is forty years old, large and well-built. He was a seaman till twelve years ago, when he took to railroad work and mining, being employed sometimes at one and sometimes at the other. He was working in a mine when he became ill. His habits as to liquor had been very moderate. He once had gonorrhea, but he denies other venereal disease. Five years ago, he was ill with rheumatism in the shoulders, accompanied by some local tenderness and swelling. This kept him in bed one week and interrupted his work for three weeks. Otherwise he enjoyed good health till one week before the onset of his present illuess. During that week, he felt drowsy and languid; yet he kept at work. The night before the attack, he went to bed feeling pretty well, and he did not notice anything peculiar about himself. The next morning his companion in the hut waked him up to ask him what the matter was. He answered that nothing was wrong; but his friend insisted that there was a noise to be heard inside of him, as if a bloodvessel had given way. Then he listened, and he also could hear it. On further investigation by him and his friends, it was found that this sound could be heard at a distance of eight feet. Since then, shortness of breath has prevented his doing any work. The dyspnea was greater the first three months than since. The event occurred four months before I saw him.

On examination there were found a water-hammer pulse, a pistol-shot sound in the arteries, a beautiful capillary pulse in the lips and in the nails, and an aortic regurgitant murmur with peculiarities about to be described. The heart was hypertrophied, with its apex in the sixth space and slightly displaced to the left. Over the aortic valve there was a loud diastolic murmur, which could be beard not only there, but two inches from the man without touching him at all, and over his entire body: the thorax and abdomen; the neck, up to the level of the ears; in front of the ears; at the angle of the jaw; the occiput; the upper part of the humeri; the outer part and top of the shoulders; and downwards to the crest of the iliac bones, back and front.

It is interesting to note that while the murmur was audible over the humerus it was not to be detected over the brachial artery. It seemed to be conducted by the bony skeleton and the muscles rather than by the blood-vessels; which conclusion other observers have arrived at in similar cases.

Of course, what had happened to this man was the sudden rupture of an already diseased aortic valve.

Gifts to the Medical Department of Yale University.- In the report of the Treasurer of Yale University it is stated that gifts to the Medical Department during the past year amounted to $\$ 2,600$, of which $\$ 1,800$ was given by Mrs, H. Farnam. 